\title{
Performance of European Wood Species in Above Ground Situations After 10 Years of Weathering: Evidence of a Positive Impact of Proper Design
}

\author{
Magdalena Kutnik, Martine Gabillé and Mathilde Montibus \\ Technological Institute FCBA, Allée de Boutaut, BP 227, 33028 Bordeaux Cedex, France. \\ magdalena.kutnik@fcba.fr,martine.gabille@fcba.fr, mathilde.montibus@fcba.fr
}

\begin{abstract}
Most of European native wood species used outdoors are expected to last less than 10 years if left untreated and exposed to severe environmental conditions such as high humidity and biological agents. However, the current classification of wood's natural durability based on EN standards does not fully reflect real end-use conditions, often underestimating wood's performance in use. In addition, the importance of design details and the role they play in enhancing service life, especially in the case of outdoor applications, is often neglected. With the aim of evaluating the positive impact of proper design on wood's service life, large-scale experimental devices, manufactured according to different designs (water draining / trapping) from six native wood species, were installed in 2009 in two French cities benefiting from different climatic conditions (oceanic / continental). The results of the evaluation carried out after 10 years of natural weathering demonstrated that (1) significant differences in the ability to withstand decay over time exist depending on the selected design details and the climatic conditions encountered in the experimental fields; (2) high variability in the resistance of non-durable spruce and poplar wood against fungal decay was noticed for each tested design, but with an unexpected high percentage of elements performing very well; (3) the moderately durable heartwood of larch, maritime pine and Douglas fir was mostly unaffected by decay even under severe conditions of exposure to rain (decking modules), suggesting these species may have greater value for outdoor applications without any preservative biocidal treatment than previously assumed.
\end{abstract}

Keywords: Natural Durability, Service Life, Performance, Design, Natural Weathering, Decay.

\section{Introduction}

The service life of a wooden structure is the period of time after installation during which it meets the initial performance requirements, such as mechanical strength, and before replacement is needed. This depends on many factors, some being natural and beyond human control, such as wood's inherent characteristics and environmental factors (wind, rain, sun, biological decay agents), and some a result of man's actions, such as design and maintenance.

The majority of European native timber species of economic importance for the building sector are regarded as naturally moderately or poorly durable with regards to biological degradation when used for outdoor applications, such as cladding and decking. In geographical areas where biological risk is high, they are frequently expected to last less than 10 years when left untreated and exposed to severe environmental conditions such as high humidity. As a consequence, in order to ensure long-lasting products, architects tend to choose durable tropical hardwoods or native woods with enhanced durability (modified or preservative treated) rather than moderately durable European wood species whose performance over time is doubtful.

However, the importance of design details and the role they play in enhancing wood's service life, especially in the case of outdoor applications, is often neglected. Indeed, premature fungal degradation of wood is frequently the consequence of inappropriate use, poor design or mistakes made during the installation, generating water traps and thus increasing the wood's 
moisture content up to a level allowing the initiation of decay.

The performance of wooden structures in terms of service-life relies both on wood's natural durability and on its exposure to weathering and biological risk. Natural durability is beyond our control, but the severity of exposure to environmental parameters can be reduced by good practices such are proper design, proper installation and proper maintenance. The objective of this study is to demonstrate that proper design of wooden structures meant for outdoor use is crucial to providing products whose service life meets the market's needs and the final users' expectations.

\section{Experimental Set-up}

Large experimental structures were constructed from six wood species, selected for their economic importance for the construction industry and different natural durability against fungal decay according to EN 350 (2016). They mimicked wooden constructions used outdoors above ground: cladding, decking, posts, inclined beams, assemblies, and log house outer walls (Figure 1). In order to compare their performance under different climatic conditions, the test devices were installed in 2009 in the French cities of Bordeaux and Charrey-sur-Saône (oceanic and continental climates, respectively). The full description of the experimental set up is given in Kutnik et al., (2011).

\subsection{Selected Timber Species}
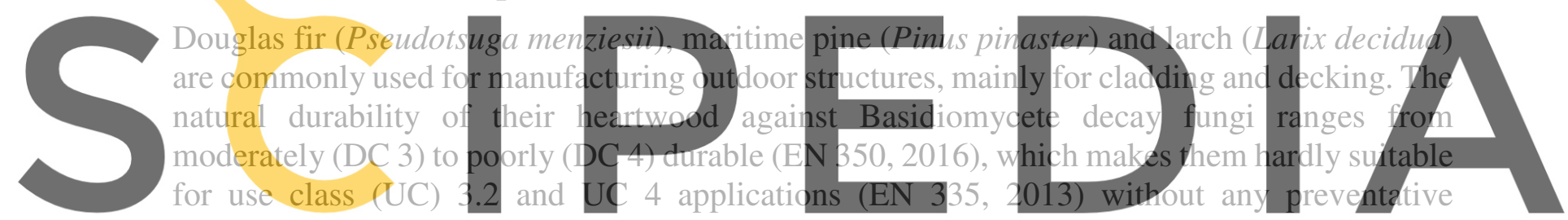

preservative treatment, especially where long service life is expected (>10 years).

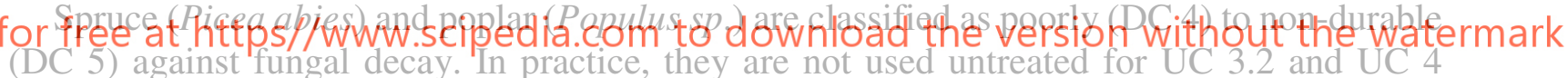

applications. In our study spruce and poplar were used as reference non-durable species, expected to decay to some extent over a period of 10 years of exposure to weathering. Different levels of decay were expected depending on the design selected for manufacturing particular experimental devices. European oak (Quercus robur), classified as durable (DC 1-2), was used as the reference durable wood species.

\subsection{Design Details}

Each type of construction comprised both water-trapping and water-draining design details. The results presented in this paper mainly concern the decking modules and the post-to-beam connections, with the design details used for manufacturing them being described in subsequent sections. Since, based on visual inspection only, the remaining construction types (log walls, posts and inclined beams) provided less interesting input, it was decided that they will be the subject of further investigation involving other tools later on. 


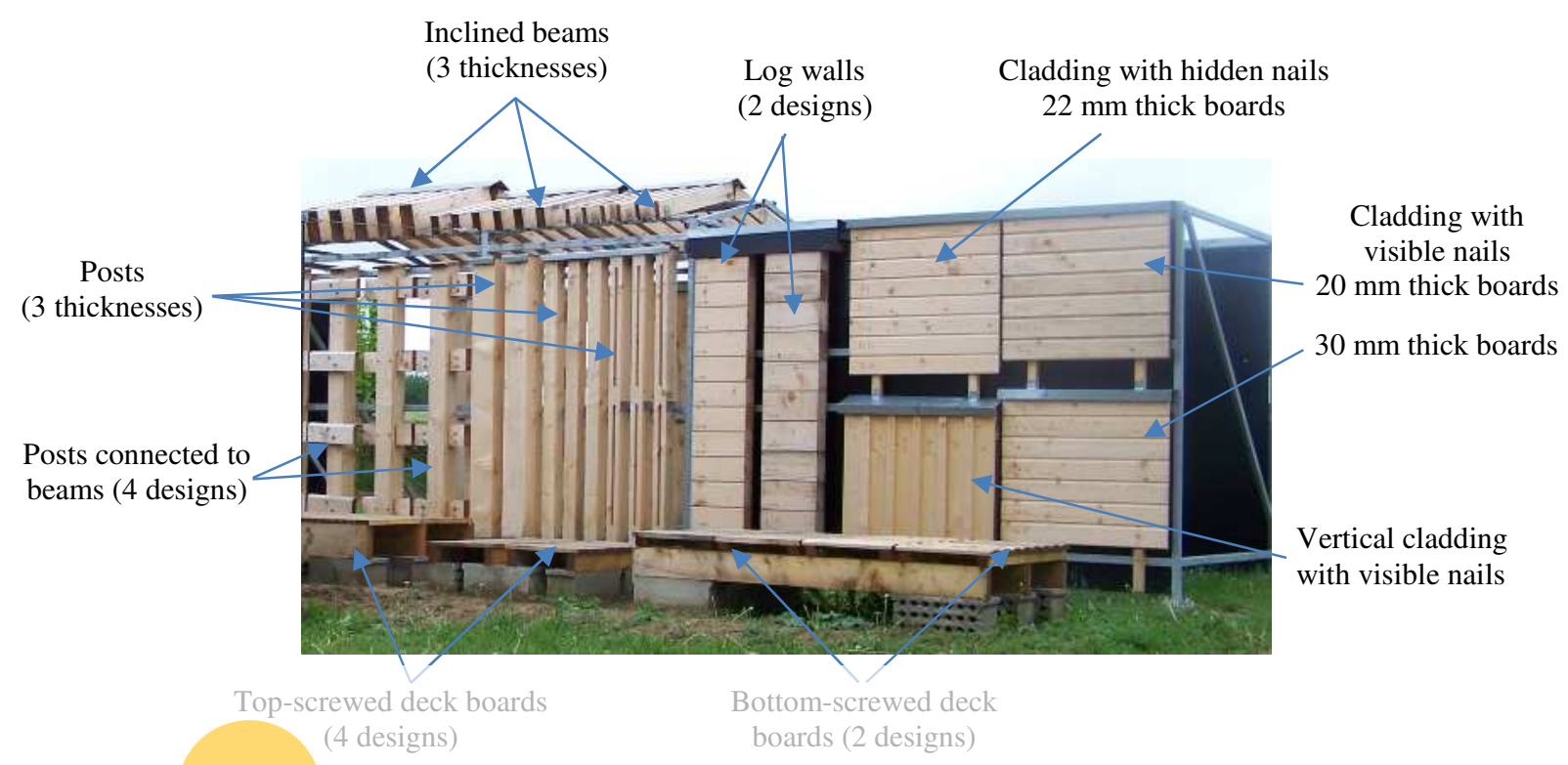

Figure 1. Experimental site in Charrey-sur-Saône, France - examples of devices made from poplar.

\subsubsection{Decking Modules}
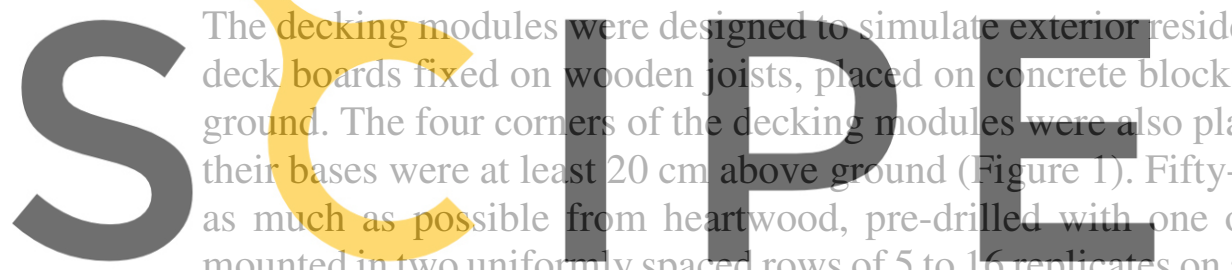

mounted in two uniformity spa
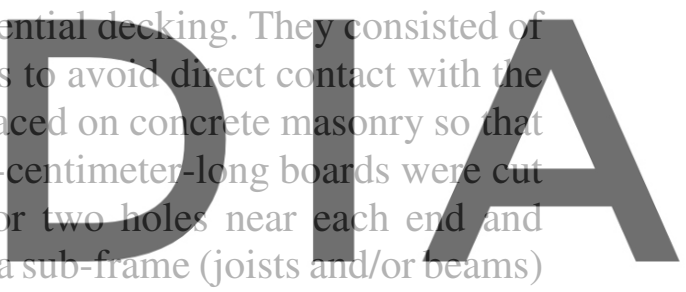

using stainless steel screws.

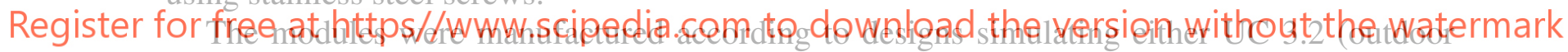

unprotected, without permanent water accumulation) or UC 4 (horizontal, above ground, with

water accumulation over long periods of time) conditions according to the French FD P 20-651 (2011), thus representing different levels of risk with regard to the probability of fungal decay. The differences between the selected designs were the thickness, width and shape of the deck boards, the way of screwing the boards on the joists beneath (top or bottom screwing) and the typology of the wood-to-wood contact zones (water draining or water-trapping).

Design A, being the most traditional decking design, was expected to represent the worstcase scenario of exposure to water accumulation (on the wood's surface, on the screws' top, at the interface between the boards and the joists beneath). Designs B and C employed thicker boards, wider (B) or thinner (C) than design A. Designs D, E and F included different details avoiding water trapping and/or improving water drainage of the deck's surface and thus were expected to perform better than designs $\mathrm{A}, \mathrm{B}$ and $\mathrm{C}$.

Six decking modules were constructed from spruce and poplar (one according to each design type). Two modules were constructed from maritime pine, larch, Douglas fir and oak, according to designs $\mathrm{A}$ and $\mathrm{F}$, expected to represent respectively the worst and the best case scenario with regard to fungal decay. The construction details are described in Kutnik and Montibus (2019). 


\subsubsection{Cladding Units}

Cladding units of $1 \mathrm{~m} \times 1 \mathrm{~m}$ were built according to four different designs, the main differences being the thickness $(20$ or $30 \mathrm{~mm}$ ) of the test boards, the way of assembling and screwing them on the battens (tongue and groove boards with visible nails or lap joint boards with hidden nails) and the orientation of the wood's fibers (three horizontal and one vertical cladding) (Figure 1). Sixteen cladding units ( 8 spruce +8 poplar) were installed in a setting that either allowed $(4+$ 4 ) or prevented $(4+4)$ their direct exposure to wind-driven rain. The end-grain of the vertically exposed boards was protected from rainwater by stainless steel sheets.

\subsubsection{Posts Connected to Beams}

Posts were screwed to metallic frames, with end-grain protected from rainwater by stainless steel sheets. Beams were connected to posts using two joining types representative of traditional carpentry: the mortise-and-tenon joint and the cross lap joint. Two innovative types of joints, reducing the wood-to-wood contact zones and allowing for efficient water drainage from the two connected elements, were manufactured as well (Figure 2). All elements were connected using stainless steel fasteners. Sixteen posts ( 8 spruce +8 poplar $)$ were installed in a setting that either allowed $(4+4)$ or prevented $(4+4)$ their direct exposure to wind-driven rain.
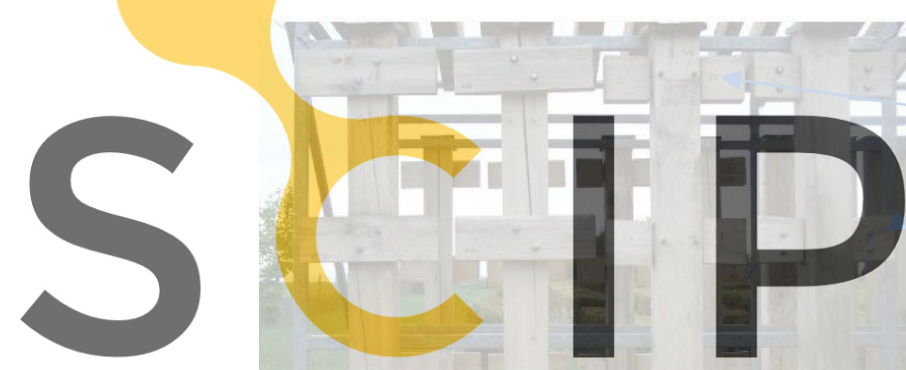

\section{Mortise and tenon joint}
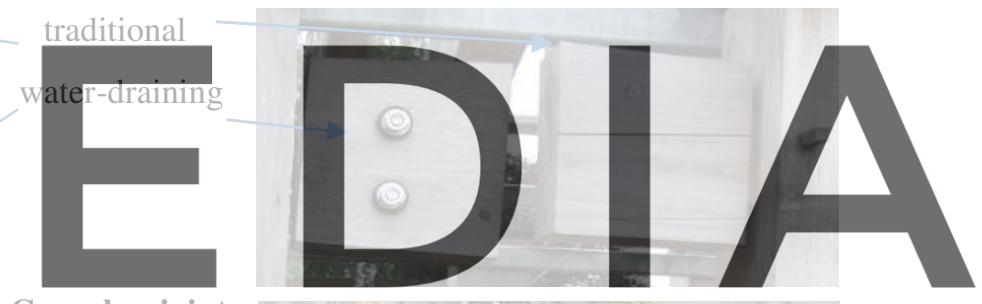

Cross lap joint

to tolowbndoad
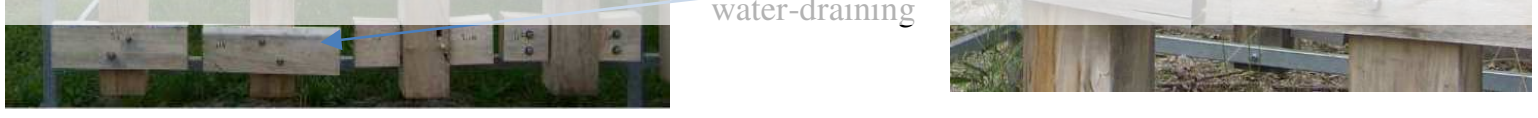

Figure 2. Poplar posts connected to beams in Charrey-sur-Saône, France.

\section{Rating of the Fungal Decay}

Non-destructive inspections of the deck boards were performed periodically according to a procedure similar to the one recommended in the standard AWPA E25-13 (2014). The decay inspection method consisted of gentle probing of board surfaces, checks and end-grain with a dull metal spatula for signs of softening or cavities. Special attention was paid to areas of high moisture content, discoloration or collapse that were visible on the surface and to areas sounding hollow or dull when tapped with the blunt end of the spatula.

The fungal degradation of exposed wooden elements was evaluated in 2019, after 10 years of exposure to weathering, following a rating scale ranging from " 0 " (sound, no evidence of fungal attack) to " 4 " (structural breakdown caused by decay). The rating scale used was adapted 
from EN 252 (2014) and AWPA E25-13 (2014) (for more details see Kutnik and Montibus, 2019). The scale and the description of the corresponding damage are presented in Table 1.

Table 1. Description of the rating scale used for the assessment of fungal decay.

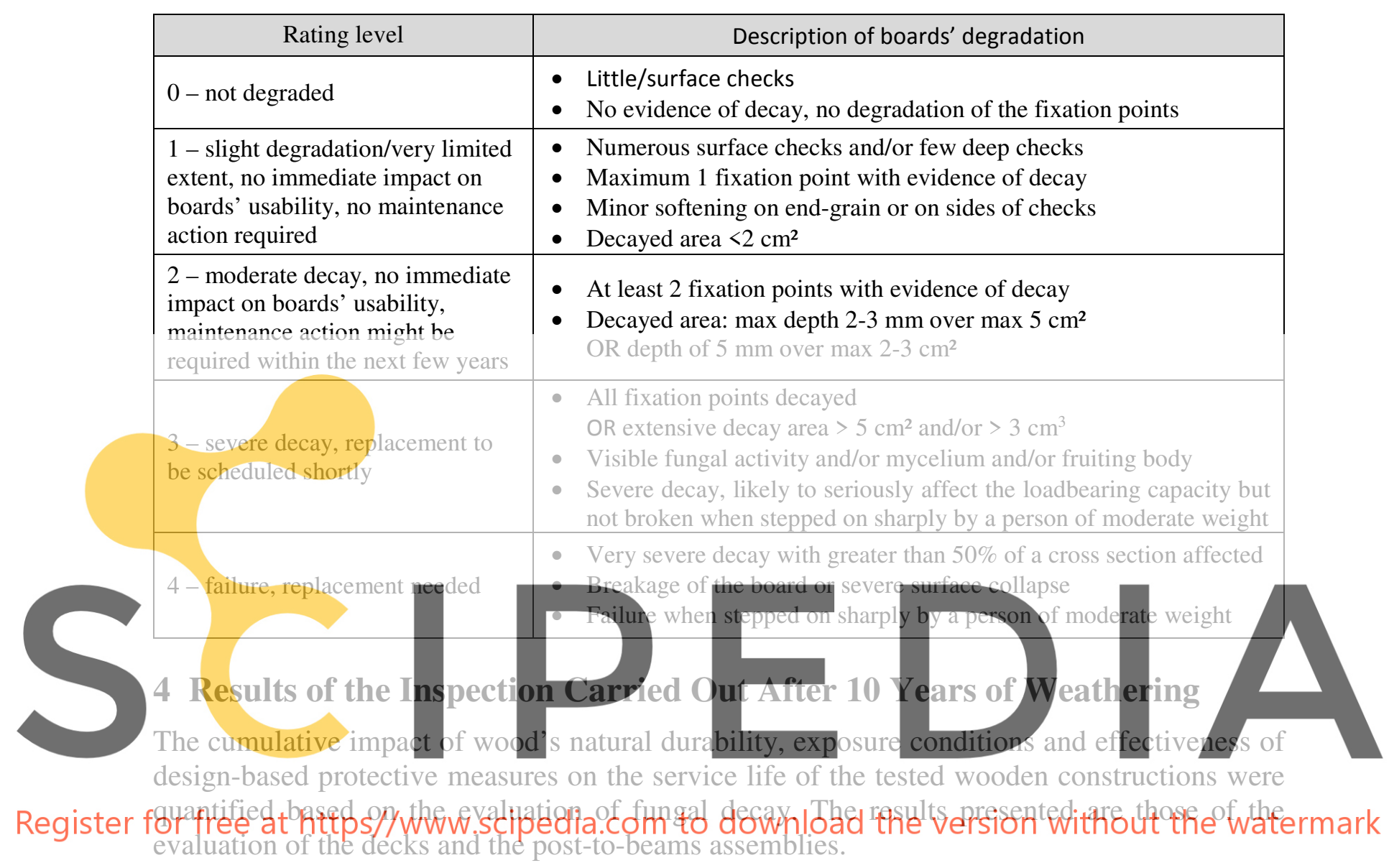

\subsection{Assessment of the Decking Modules With Regard to Fungal Decay}

The results of the evaluation are presented in Table 2 for each wood species, design type and location ("Bord" for Bordeaux and "Charr" for Charrey-sur-Saône).

The upper surface of the decks manufactured from oak, Douglas fir, larch and maritime pine (the latter in Charrey-sur-Saône only) showed either no or very little visible decay or decay limited to parts of the boards which were assumed to be residual non-durable sapwood. For this reason, the decks were left in place in order to allow future evaluation and only the top side of the boards was rated. After 10 years of weathering, the impact of the selected design details used in the decks manufactured from these four wood species was not measurable yet.

Oak (the durable reference species) resisted fungal deterioration over time, with 14 out of the 16 boards rated " 0 " for both design A and F in Bordeaux and all 16 in Charrey-sur-Saône rated likewise. Deck boards made from moderately to slightly durable larch and Douglas fir resisted deterioration over time on both test sites, the great majority of deck boards being rated " 0 " for fungal decay. A few boards reached the decay level of " 2 " and " 3 ", but this degradation concerned only the residual sapwood parts. Deck boards made from maritime pine resisted degradation in Charrey-sur-Saône to the same extent as larch and Douglas fir, but high 
variability was observed in Bordeaux (deck boards rated from "0" to "4"). Maritime pine boards comprised a lot of sapwood and this is certainly the main cause of their premature decay.

Table 2. Number of deck boards of each wood species and design type rated 0 to 4.

\begin{tabular}{|c|c|c|c|c|c|c|c|c|}
\hline \multirow{2}{*}{$\begin{array}{c}\text { Wood } \\
\text { species }\end{array}$} & \multirow{2}{*}{$\begin{array}{l}\text { Design } \\
\text { type }\end{array}$} & \multirow{2}{*}{ Location } & \multicolumn{5}{|c|}{ Number of boards per rating level } & \multirow{2}{*}{$\begin{array}{l}\text { Number } \\
\text { of boards }\end{array}$} \\
\hline & & & Rating 0 & Rating 1 & Rating 2 & Rating 3 & Rating 4 & \\
\hline \multirow{4}{*}{ oak } & \multirow{2}{*}{ A } & Bord & 14 & 1 & 1 & 0 & 0 & 16 \\
\hline & & Charr & 16 & 0 & 0 & 0 & 0 & 16 \\
\hline & \multirow{2}{*}{$\mathrm{F}$} & Bord & 14 & 2 & 0 & 0 & 0 & 16 \\
\hline & & Charr & 16 & 0 & 0 & 0 & 0 & 16 \\
\hline \multirow{4}{*}{ larch } & \multirow{2}{*}{ A } & Bord & 13 & 3 & 0 & 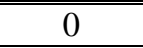 & 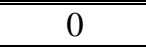 & 16 \\
\hline & & Charr & 15 & 1 & 0 & 0 & 0 & 16 \\
\hline & \multirow{2}{*}{$\mathrm{F}$} & Bord & 13 & 1 & 2 & 0 & 0 & 16 \\
\hline & & Charr & 14 & 1 & 0 & 1 & 0 & 16 \\
\hline \multirow{4}{*}{$\begin{array}{l}\text { Douglas } \\
\text { fir }\end{array}$} & \multirow{2}{*}{ A } & Bord & $\overline{10}$ & $\overline{2}$ & $\overline{3}$ & 1 & 0 & 16 \\
\hline & & Charr & 15 & 1 & 0 & 0 & 0 & 16 \\
\hline & \multirow{2}{*}{ F } & Bord & 10 & 1 & 2 & 3 & 0 & 16 \\
\hline & & Charr & 14 & 1 & 0 & 1 & 0 & 16 \\
\hline \multirow{4}{*}{$\begin{array}{l}\text { maritime } \\
\text { pine }\end{array}$} & \multirow{4}{*}{ F } & Bord & 6 & 3 & 2 & 4 & 1 & 16 \\
\hline & & Charr & 13 & 1 & 0 & 2 & 0 & 16 \\
\hline & & Bord & 4 & 0 & 3 & 4 & 5 & 16 \\
\hline & & Charr & 15 & 0 & 0 & 1 & 0 & 16 \\
\hline \multirow{7}{*}{ spruce } & \multirow{4}{*}{ B } & Bord & 0 & 2 & 6 & 6 & 2 & 16 \\
\hline & & Charr & 0 & 5 & 8 & 3 & 0 & 16 \\
\hline & & Bord & 0 & 1 & 1 & 8 & 0 & 10 \\
\hline & & Charr & $\theta$ & 0 & 3 & 4 & 5 & \\
\hline & C & Charr & $\frac{5}{0}$ & $\frac{18}{13}$ & $\frac{6}{6}$ & $\frac{5}{14}$ & $\frac{2}{3}$ & \\
\hline & & Bord & 1 & 5 & 5 & 1 & 4 & 16 \\
\hline & & Charr & 0. & 5 & 5 & 4 & 3 & 16 \\
\hline
\end{tabular}

Register for free at https//W\$bWl.scipedia.com to download the version without the watermark

\begin{tabular}{|c|c|c|c|c|c|c|c|c|}
\hline & \multirow{3}{*}{$\mathrm{F}$} & & & & & & & \\
\hline & & Bord & 5 & 5 & 1 & 1 & 4 & 16 \\
\hline & & Charr & 9 & 5 & 0 & 2 & 2 & 18 \\
\hline \multirow{12}{*}{ poplar } & \multirow{2}{*}{ A } & Bord & 0 & 0 & 8 & 5 & 3 & 16 \\
\hline & & Charr & 0 & 12 & 2 & 1 & 1 & 16 \\
\hline & \multirow{2}{*}{ B } & Bord & 0 & 1 & 4 & 5 & 0 & 10 \\
\hline & & Charr & 0 & 10 & 1 & 1 & 0 & 10 \\
\hline & \multirow{2}{*}{$\mathrm{C}$} & Bord & 0 & 7 & 16 & 7 & 2 & 36 \\
\hline & & Charr & 0 & 16 & 11 & 9 & 0 & 36 \\
\hline & \multirow{2}{*}{$\mathrm{D}$} & Bord & 0 & 0 & 6 & 7 & 3 & 16 \\
\hline & & Charr & 0 & 10 & 3 & 3 & 0 & 16 \\
\hline & \multirow{2}{*}{$\mathrm{E}$} & Bord & 0 & 4 & 6 & 5 & 1 & 16 \\
\hline & & Charr & 0 & 11 & 4 & 0 & 1 & 16 \\
\hline & \multirow{2}{*}{$\mathrm{F}$} & Bord & 0 & 4 & 6 & 5 & 1 & 16 \\
\hline & & Charr & 0 & 6 & 6 & 2 & 2 & 16 \\
\hline
\end{tabular}

Bordeaux/Charrey: dark orange/green colour = highest number of decks with the same rating; light orange/green colour $=$ dispersion of ratings over the deck boards 
Non-durable poplar and spruce decks were dismantled and the boards were individually rated for fungal decay. High variability was recorded in the extent of fungal degradation depending on the tested design and exposure site.

Spruce bottom-screwed deck boards (design types E and F) were significantly less decayed (high number of boards with no - rating " 0 " - or very little - rating " 1 " - decay) than topscrewed ones, except boards assembled according to design $\mathrm{C}$ ( $5 \mathrm{~cm}$ wide, 1 screw at each end). These boards showed high variability in their resistance to fungal decay and better overall performance than types A, B and D, especially in Bordeaux. The general trend is that decks installed in Bordeaux were slightly less decayed than in Charrey-sur-Saône.

Poplar deck boards were significantly less decayed in Charrey-sur-Saône than in Bordeaux. However, the impact of the design was less obvious than in the case of spruce. Similar performance was found for all decks irrespectively of their design in Charrey-sur-Saône and slightly better performance of bottom-screwed boards was observed in Bordeaux.

\subsection{Post-to-Beams Assemblies}

The assemblies evaluated on the test devices made from oak, larch, Douglas fir and maritime pine were all found sound after 10 years of exposure, irrespective of the tested design.

Spruce and poplar wood mortise-and-tenon and cross lap assemblies constructed according to water-draining designs were all sound in both test sites, irrespective of whether they were or were not directly exposed to wind-driven rain. Assemblies constructed according to watertrapping designs were decayed to different extent, depending on the woed specias (spruce w
less decayed than poplar) and test sito (test devices installed in Charrey-sur-Saône were less less decayed than poplar) and test sito (test devil
decayed than those in Bordeaux). Decay fung both elements (posts and elements connected to th of the assembly, Figure 3 shows that

either sound, when constructed according

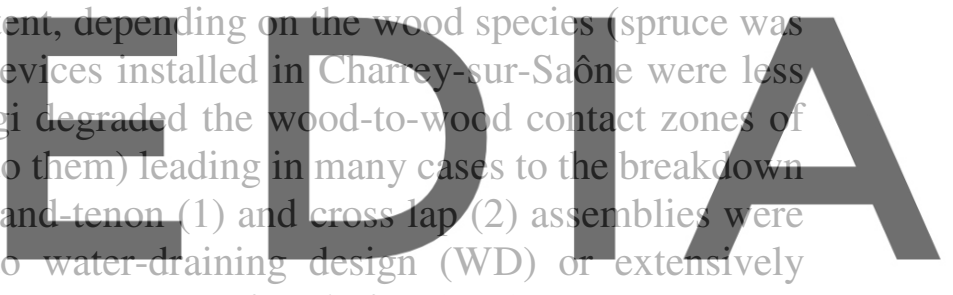
decayed by fungi, when constructed according to water-trapping design (WT).

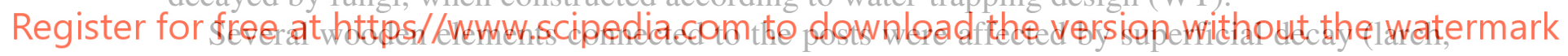
maritime pine, poplar and spruce), located mostly on their upper part and/or in sapwood parts.
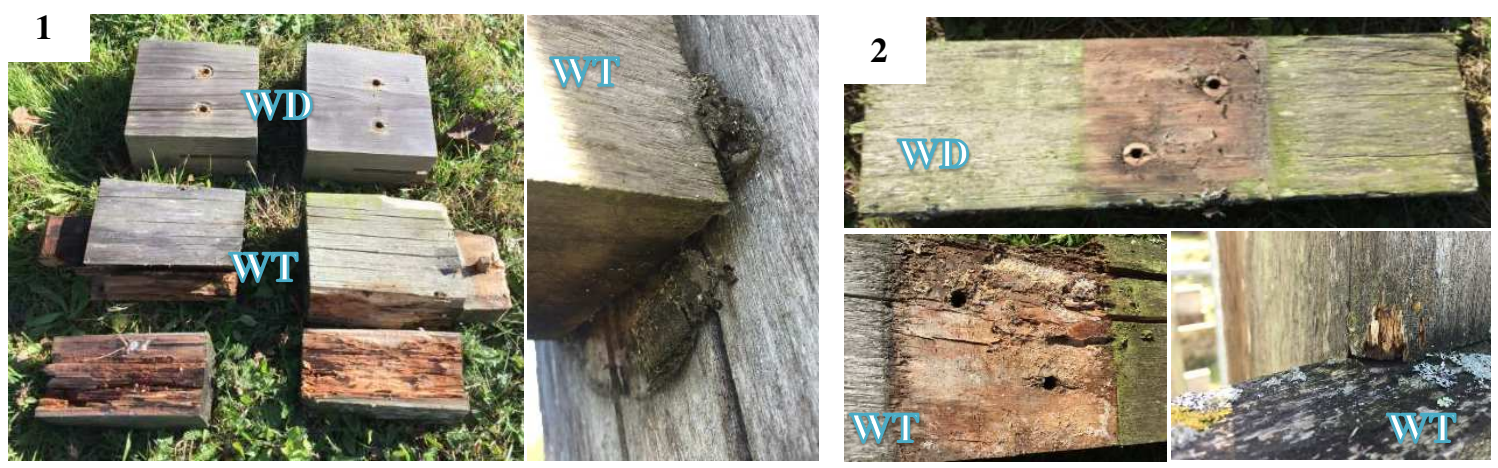

Figure 3. Poplar posts connected to beams in Charrey-sur-Saône, France. 


\section{Conclusions}

- Significant differences in the ability of wood to withstand decay over time were observed depending on the selected design details used and the surrounding climatic conditions, especially in the case of non-durable spruce and poplar wood;

- The continental climate was less favorable to decay fungi than the oceanic one;

- A positive effect of the water draining designs was demonstrated for decks and assemblies made from non-durable spruce and poplar wood, with fewer elements being affected by fungal decay and lesser extent of decay;

- The moderately durable heartwood of larch, maritime pine and Douglas fir was unaffected by decay, even under severe conditions of exposure to rain and water accumulation (decking). This suggests that these wood species could be used without any preservative treatment, provided the sapwood has been removed, for manufacturing outdoor structures whose service life could by far exceed 10 years;

Wooden structures made of non-durable spruce and poplar showed high variability in terms of resistance against fungal decay, but with a high percentage of elements being still sound or below their limit state of use after 10 years;

European standards provide keys to proper selection of timber species (EN 350:2016), understanding of the biological risks associated with their use (EN 335:2013) and proper treatment where necessary (EN 599-1:2014). However, given the diversity of conditions under which wood may be in service, there is no direct, simple and reliable method to
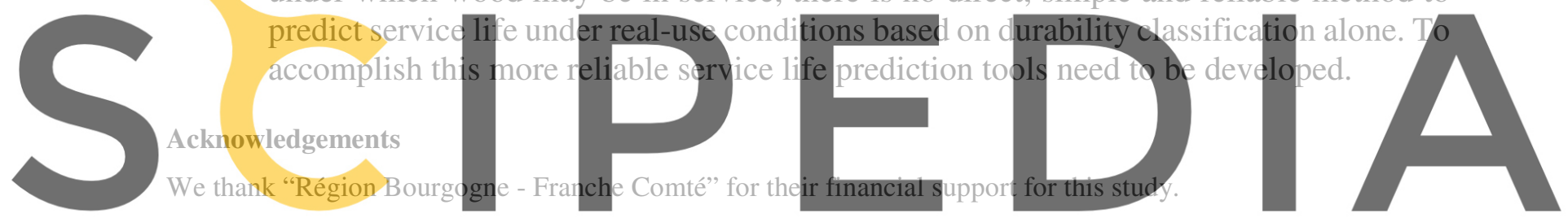

ORCID

Register for free at https//yww. scipedia. Martine Gabille: http://orcid.org/0000-0002-6614-5320

Mathilde Montibus: https://orcid.org/0000-0002-3033-017X

\section{References}

AWPA E25-13 (2014). Standard field test for evaluation of wood preservatives to be used above ground (UC 3B). Decking test.

EN 252 (2014). Field test method for determining the relative protective effectiveness of a wood preservative in ground contact. CEN.

EN 335 (2013). Durability of wood and wood-based products. Use classes: definitions, application to solid wood and wood-based products. CEN.

EN 350 (2016). Durability of wood and wood-based products - Testing and classification of the durability to biological agents of wood and wood-based materials. CEN.

EN 599-1+A1 (2014). Durability of wood and wood-based products - Efficacy of preventive wood preservatives as determined by biological tests - Part 1: Specification according to use class. CEN.

FD P 20-651 (2011). Durabilité des éléments et ouvrages en bois. Ed. AFNOR

Kutnik M., Jequel M. and Le Nevé S. (2011). Improving the Durability and Service Life of Wooden Components in Outdoor Applications: the French Approach. Proceedings of the 12th International conference on Durability of Building Materials and Components, 12-15 April 2011, Porto, Portugal.

Kutnik M. and Montibus M. (2019). Durability by design: a case study of the performance of wooden decks after 9.5 years of natural weathering. Proceedings of the Annual Meeting of the International Group on Wood Protection, Québec City, Québec. IRG/WP 19-20648 